\title{
Performance Appraisal of Technological Innovation in Military-Civilian Enterprises-Empirical Evidence from Jiangsu Military-Civilian Integration Enterprises
}

\author{
Xiao, L. J. ${ }^{1} \&$ Xun, Z. X. ${ }^{1}$ \\ ${ }^{1}$ Department of Economics and Management, Nanjing University of Aeronautics and Astronautics, PR China \\ Correspondence: Xun, Z. X., Department of Economics and Management, Nanjing University of Aeronautics \\ and Astronautics, No.29, Jiangjun Road, Nanjing 210000, Jiangsu Province, PR China. E-mail: \\ xunzx1997@outlook.com
}

Received: July 31, 2020

Accepted: August 18, 2020

Online Published: October 20, 2020

doi:10.5539/ijbm.v15n11p79

URL: https://doi.org/10.5539/ijbm.v15n11p79

\begin{abstract}
The development of military-civilian dual-use high-tech and joint technological innovation is important for military-civilian integration enterprises to develop in-depth military-civilian integration. Taking 10 military-civilian listed enterprises in Jiangsu Province as the research objects, and using DEA-BBC model and DEA-Malmquist index method, this paper constructs an evaluation system for technological innovation performance of enterprises, evaluates and studies the innovation performance from 2016 to 2019. The research shows that the technological innovation performance of enterprises is generally low. The main reasons of this situation are backward technology, low resource utilization, and the uneven management capabilities of enterprises. In addition, this paper provides some suggestions for improving the technological innovation performance of military-civilian enterprises.
\end{abstract}

Keywords: Military-civilian integration, technological innovation performance, DEA model.

\section{Introduction}

In the context of globalization, the development of military-civilian integration has become a national strategy, and innovation has become the country's most important weapon. The results of military-civilian integration innovation can also play an important role in the implementation of the national innovation-driven strategy and the construction of an innovative country. There are many military science and technology enterprises in Jiangsu Province, and many civilian enterprises have entered the field of defense science and technology with leading technology, providing excellent technical products for the defense and military departments. Under the background of domestic military-civilian integration and deep integration, it is an inevitable trend in Jiangsu to carry out research on the innovation and development of military and civilian industries. This article will define the meaning of the performance of the military-civilian integration technology innovation system, clarify its structure, nature and characteristics, and propose theoretical methods of evaluation to provide basis and guidance for the establishment of a performance evaluation system for military-civilian integration enterprises in Jiangsu Province.

\section{Literature Review}

Military-civilian integration technology innovation is an important innovation model proposed based on the interaction between major national needs and technological innovation capabilities. This article uses technological innovation as a starting point to comb the domestic and foreign research status of military-civilian integration technology innovation.

In 1994, the US Congress Office of Technology Evaluation defined the concept of military-civilian integration as "a process of organically combining the defense industry base with the civilian industrial base, so that military-civilian technologies, manufacturing processes, personnel, and equipment can meet national defense and commercial needs." Kulve (2013) proposed the concept of a comprehensive military-civilian technology and industrial base. Ross (2017) conducted research on the factors affecting the operational performance of military-civilian integration innovation teams, and provided effective guidance for the practical activities of military-civilian integration innovation teams. At present, the future trend of the world's military activities will 
be a wave of "disruptive technology" innovations with great influence. Without exception, these technologies are typical military and civilian technologies. With the continuous overlap of the three major areas of science and technology, industry, and military, the boundaries between military technology and civilian technology have become increasingly blurred, and the degree of overlap has become higher. This situation shows that the world's major powers have entered the era of military and civilian technology. The source of military technological innovation capabilities lies in the socio-economic and technological system.

Accelerating the construction of a military-civilian integration technology innovation system and improving the ability of independent innovation in national defense are important to promote the transformation of China's military construction. In terms of innovation and development of military-civilian integration: Zhao Y (2019) believes that for military-civilian integration to achieve innovative development, integration should be achieved from three aspects: the generation, transformation, and dissemination of results according to the needs of different goals. Hu HA and Liu LJ (2015) judged that our country's military-civilian integration innovation is still in a state of low-level coordination, and improving the degree of military-civilian integration innovation coordination requires the government to actively play a coordinating and guiding role. In terms of establishing an innovation model: Lan DX and Wu YF (2018) pointed out that the development of military-civilian integration is a system engineering, establishing subsystem models from the perspective of complex systems and proposing innovative countermeasures. Shuang (2013) proposed the constituent elements of the military-civilian integration innovation main body, and analyzed the role of each main element. Yang XX and Chen B (2020) estimated the spatial measurement model based on two weight matrices of geographic proximity and R\&D capital flow, and found that defense patents have significant positive spatial correlation characteristics. Under the influence of geographic proximity and $\mathrm{R} \& \mathrm{D}$ capital flow, defense innovation performance has a significant spatial spillover effect.

Research on the establishment of military-civilian integration technology innovation performance is still in its infancy. In the early years, due to the sensitivity and unavailability of military-civilian integration data, the existing results are mainly based on qualitative analysis, in terms of empirical analysis. Objectively, the research based on performance theory on military-civilian integration technology innovation is insufficient. Especially, the construction, operation mechanism, and evaluation of the evaluation system based on enterprise micro data still lack theoretical and practical results.

\section{Model Building}

\subsection{Model Selection}

According to the existing literature, the typical methods of project performance evaluation are artificial neural network, analytic hierarchy process, and data envelopment analysis. We believe that too many subjective factors should not be mixed in the evaluation process, so as to avoid the interference of many factors such as the subjective judgment of decision-makers, which will affect the evaluation. We examined the advantages and disadvantages of various methods and selects the most suitable method, namely the data envelopment evaluation method. Data envelopment analysis is based on the concept of "relative efficiency". It uses a mathematical model to calculate the relative efficiency between decision-making units. It is a method of systematic analysis of the relative effectiveness or return to scale of the decision-making units. It can handle the comprehensive evaluation of the effectiveness of multiple input/multiple output. Multi-input/multi-output is where DEA is important and noticeable, and it is also one of its outstanding advantages.

The DEA model measures the efficiency of decision-making units from three aspects: comprehensive efficiency (also known as technical efficiency, TE), pure technical efficiency (PTE), and scale efficiency (SE), and whether it is at the forefront of production. CCR and BBC are the two most commonly used models of DEA. The CCR model is calculated under the assumption of constant returns to scale, and the $\mathrm{BBC}$ model is calculated under the assumption of variable returns to scale. It is an improvement of the CCR model. The efficiency of scale (SE) can be removed when calculating technical efficiency (TE). Influence to obtain pure technical efficiency (PTE). After that, Rolf combined the Malmquist index with data envelopment analysis, and divided the index into technical efficiency index, technological progress change index and scale efficiency. Since most military-civilian fusion companies are in a state of variable returns to scale, this paper selects the BBC model to conduct an empirical analysis on the static technological innovation performance of military-civilian fusion companies, and then uses the Malmquist index model to study dynamic efficiency trends.

Under the variable returns to scale, the input variable DEA-BBC model can be expressed as: 


$$
\left\{\begin{array}{c}
\min \left[\theta-\epsilon\left(\sum_{\mathrm{i}=1}^{\mathrm{m}} \mathrm{S}_{\mathrm{i}}^{-}+\sum_{\mathrm{r}=1}^{\mathrm{s}} \mathrm{S}_{\mathrm{r}}^{+}\right)\right] \\
\text {st. } \sum_{\mathrm{j}=1}^{\mathrm{n}} \lambda_{\mathrm{j}} \mathrm{x}_{\mathrm{ij}}+\mathrm{S}_{\mathrm{r}}^{-}=\theta_{\mathrm{xij} 0} \\
\sum_{\mathrm{j}=1}^{\mathrm{n}} \lambda_{\mathrm{j}} \mathrm{y}_{\mathrm{rj}}-\mathrm{S}_{\mathrm{i}}^{+}=\theta_{\mathrm{yrj} 0} \\
\sum_{\mathrm{j}=1}^{\mathrm{n}} \lambda_{\mathrm{j}}=1 \\
\lambda_{\mathrm{j}} \geq 0(\mathrm{j}=1,2, \cdots, \mathrm{n}) \\
\mathrm{S}_{\mathrm{i}}^{-} \geq 0, \mathrm{~S}_{\mathrm{r}}^{+} \geq 0, \theta \geq 0
\end{array}\right.
$$

The Malmquist index formula can be expressed as:

$$
M_{0}\left(X_{t+1}, Y_{t+1}, X_{t}, Y_{t}\right)=\frac{D_{0}^{t+1}\left(X_{t+1}, Y_{t+1}\right)}{D_{0}{ }^{t}\left(X_{t}, Y_{t}\right)} \times \sqrt{\frac{D_{0}^{t}\left(X_{t+1}, Y_{t+1}\right)}{D_{0}{ }^{t+1}\left(X_{t+1}, Y_{t+1}\right)} \times \frac{D_{0}{ }^{t}\left(X_{t}, Y_{t}\right)}{D_{0}{ }^{t+1}\left(X_{t}, Y_{t}\right)}}
$$

In formula (2), $\frac{D_{0}{ }^{t+1}\left(X_{t+1}, Y_{t+1}\right)}{D_{0}{ }^{t}\left(X_{t}, Y_{t}\right)}$ represents EFFCH (Technical Efficiency Change), $\frac{D_{0}{ }^{t}\left(X_{t+1}, Y_{t+1}\right)}{D_{0}{ }^{t+1}\left(X_{t+1}, Y_{t+1}\right)} \times$

$\frac{D_{0}^{t}\left(X_{t}, Y_{t}\right)}{D_{0}{ }^{t+1}\left(X_{t}, Y_{t}\right)}$ means TECHCH (Technological Progress Change). In the case of variable returns to scale, technical efficiency changes (EFFCH) can be further decomposed into pure technical efficiency changes (PC) and scale efficiency changes (SE). For this reason, formula (2) can be rewritten as formula (3):

$$
\begin{gathered}
M_{0}\left(X_{t+1}, Y_{t+1}, X_{t}, Y_{t}\right)=\frac{S_{0}^{t}\left(X_{t}, Y_{t}\right)}{S_{0}{ }^{t}\left(X_{t+1}, Y_{t+1}\right)} \times \frac{D_{0}^{t}\left(X_{t+1}, Y_{t+1}\right)}{D_{0}{ }^{t}\left(X_{t}, Y_{t}\right)} \times \sqrt{\frac{D_{0}^{t}\left(X_{t+1}, Y_{t+1}\right)}{D_{0}{ }^{t+1}\left(X_{t+1}, Y_{t+1}\right)} \times \frac{D_{0}^{t}\left(X_{t}, Y_{t}\right)}{D_{0}{ }^{t+1}\left(X_{t}, Y_{t}\right)}} \\
T F P C H=E F F C H \times T E C H C H=S E C H \times P E C H \times T E C H C H
\end{gathered}
$$

The technical efficiency value calculated by the model can be used to measure the utilization of invested personnel and capital by the enterprise. The lower the technical efficiency value, the lower the utilization rate of personnel and capital, and the lower the output efficiency. The higher the technical efficiency value, the higher the utilization rate of personnel and capital, and the higher the output efficiency.

\subsection{Index Selection}

Previous studies mainly used a macro perspective to evaluate the innovation system from the dimensions of government policy, asset investment, and achievement transformation, but it has been unable to fully evaluate the core capabilities of technology to promote development. According to the existing research involving innovation performance evaluation, representative conclusions are as follows: 1. Cosh A (2012) believe the evaluation should based on whether the enterprise implements innovation and the degree of innovation commercialization. 2. Han B and Su Y (2018) believe that indicators to measure innovation performance should be considered in terms of process and results.

Based on the research results of many scholars, the indicators for conducting the evaluation system of military-civilian integration enterprises is shown in Table 1.

Table 1.The evaluation index system

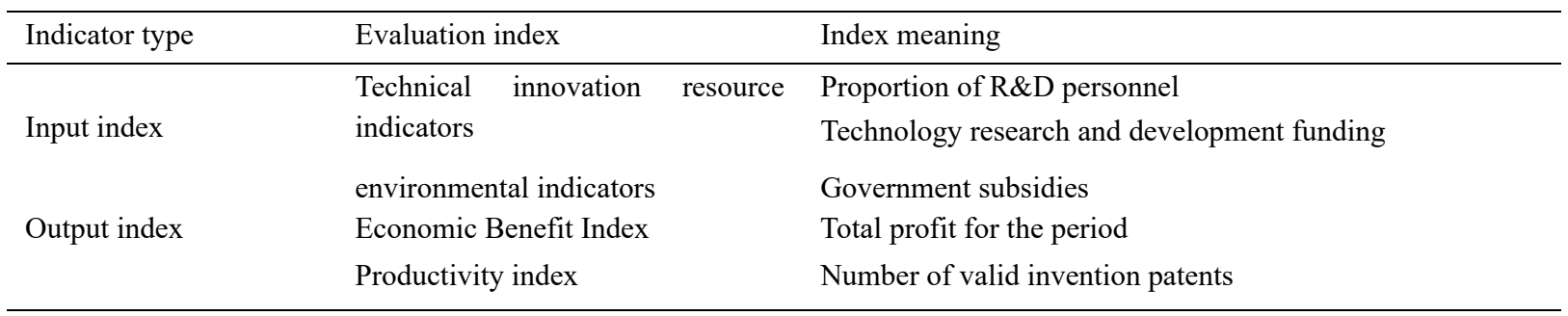

The input indicators are: Firstly, potential technological innovation resource indicators, including the number of enterprise engineering and technical personnel. From the perspective of resource allocation, the higher the proportion of technical R\&D personnel, the more streamlined management personnel, the simpler the management structure, which enhances the accuracy of important information in the transmission process, at the same time, it reduces the internal friction of the enterprise caused by excessive management personnel, and 
improves the operation ability of the enterprise. The most important task of military-civilian integration enterprises is to study the transformation and innovation of high-tech, military-industrial technology and civilian technology. Technology R\&D funding is undoubtedly the most important investment within a company. The higher the proportion of technology R\&D funding, the less the daily loss of the company's operations and management, the more it can focus on the improvement of technological capabilities. This indicator includes the stock of human resources and the stock of economic resources, and mainly reflects the potential technology innovation ability of all companies in a certain area. Secondly, technological innovation environmental indicators, including the proportion of fiscal funds and government funding in the amount of funds raised for scientific and technological activities. The special feature of military-civilian enterprises lies in their natural relationship with the government. Government funding and subsidies represent whether policies support enterprise development. Therefore, government subsidy indicator is the best choice for evaluating the technological innovation environment.

The output indicators are: Firstly, economic efficiency indicators, including enterprise micro data such as total operating income and total profits, mainly reflecting the economic benefits brought to military-civilian integrated enterprises by technological innovation. Even with a special background, military-civilian integrated enterprises are still profitable enterprises. Only with economic benefits can there be the possibility of technological innovation. Secondly, technological innovation output capability indicators, including the number of patent applications as a percentage of national patent applications, and the number of invention patents as a proportion of the number of invention patents in the country. Since micro data is difficult to collect and quantify, this article replaces it with the number of valid patents. The output capacity of enterprise technological innovation reflects the actual effect of its various element combinations, so this indicator is the most direct and the most important indicator of the enterprise's innovation ability evaluation.

\subsection{Sample Selection and Data Processing}

Due to the confidentiality-related issues of military-civilian integration enterprises, some data are not easy to obtain, so we choose 10 military-civilian integration companies in Jiangsu Province as research samples, and the research period is 2016-2019. The specific sample companies are: Xinhaiyi, Yinhe Electronics, Tianwo Technology, Tongda Power, Helenzer, Electric Power Research Institute, Tongguang Cable, Ruite Co, Guorui Technology and Suzhou High-tech.

Table 2.Overview of 10 military-civilian listed companies

\begin{tabular}{|c|c|c|c|c|}
\hline No. & DMU & $\begin{array}{l}\text { Securities } \\
\text { code }\end{array}$ & Affiliation & Business Scope \\
\hline 1 & Xinhaiyi & 002089 & Xinhaiyi Technology Group & Communication network equipment \\
\hline 2 & Yinhe Electronics & 002519 & $\begin{array}{l}\text { Jiangsu Yinhe Electronics Co., } \\
\text { Ltd. }\end{array}$ & Network products, etc. \\
\hline 3 & Tianwo Technology & 002564 & $\begin{array}{l}\text { Suzhou Tianwo Technology Co., } \\
\text { Ltd. }\end{array}$ & Petrochemical industry \\
\hline 4 & Tongda Power & 002576 & $\begin{array}{l}\text { Jiangsu Tongda Power } \\
\text { Technology Co., Ltd. }\end{array}$ & Motor etc. \\
\hline 5 & Helenzer & 300201 & $\begin{array}{l}\text { Xuzhou Helenzer special vehicle } \\
\text { Co., Ltd. }\end{array}$ & Construction machinery, etc. \\
\hline 6 & $\begin{array}{l}\text { Electric Power } \\
\text { Research Institute }\end{array}$ & 300215 & $\begin{array}{l}\text { Suzhou Electrical Apparatus } \\
\text { Research Institute }\end{array}$ & Mechanical \& electrical equipment \\
\hline 7 & Tongguang Cable & 300265 & $\begin{array}{l}\text { Jiangsu Tongguang Electronic } \\
\text { Cable Co., Ltd. }\end{array}$ & Semiconductor chips, etc. \\
\hline 8 & Ruite Co & 600630 & $\begin{array}{l}\text { Changshu Ruite Electric Co., } \\
\text { Ltd. }\end{array}$ & Electrical components \\
\hline 9 & Guorui Technology & 600562 & Guorui Technology Co., Ltd. & Electronic equipment \\
\hline 10 & Suzhou High-tech & 600736 & $\begin{array}{l}\text { Suzhou New District High-tech } \\
\text { Industry Co., Ltd. }\end{array}$ & High-tech products \\
\hline
\end{tabular}

Since the DEA model requires both input and output index values to be non-negative, it is necessary to dimensionlessly process the financial data of these 10 military-civilian listed companies and place the evaluation 
index data in the $(0,1)$ interval. For the variable $Y_{i j}, i$ represents the number of evaluation indicators, and $j$ represents the number of DMUs in the decision-making unit. This paper chooses the extreme value method for data non-negative processing, and the dimensionless formula is as follows:

$$
Y_{i j}=0.1+\frac{X_{i j}-a_{i}}{b_{i}-a_{i}} \times 0.9
$$

In formula (5), $b_{i}=\max \left(x_{i 1}, x_{i 2}, \cdots x_{i j}\right), a_{i}=\min \left(x_{i 1}, x_{i 2}, \cdots x_{i j}\right)$.

\section{Results Analysis}

This paper uses DEAP software to conduct empirical analysis on 10 military-civilian listed companies, and obtain the performance results of each listed company. First, the DEA model is used to statically analyze the technological innovation performance of the sample companies, and then the DEA-Malmquist index method is used to dynamically analyze the technological innovation performance of the sample companies.

\subsection{Static analysis}

The relative values of the technological innovation performance of 10 sample military-civilian listed companies are shown in Table 3, reflecting the overall situation of the technological innovation performance of Jiangsu military-civilian listed companies.

It can be seen from Table 3 that in 2019, 4 sample companies have been at the forefront of innovative efficiency production (pure technical efficiency is equal to 1), namely Xinhaiyi, Helenzer, Tongguang Cable and Suzhou High-tech. These 4 companies not only achieve the effective DEA of technical efficiency, but also the effective DEA of scale efficiency, indicating that the capital investment level and innovative technology level of these 4 companies match their scale, and that the funds of the 4 companies are fully utilized, and there is no excess investment and underproduction, the DEA is effective.

Table 3. Results of enterprise performance measurement in 2019

\begin{tabular}{lllll}
\hline firm & crste & vrste & scale & Return to scale \\
\hline 1 & 1.000 & 1.000 & 1.000 & - \\
2 & 0.644 & 0.665 & 0.969 & drs \\
3 & 0.706 & 0.869 & 0.812 & drs \\
4 & 0.685 & 0.999 & 0.686 & irs \\
5 & 1.000 & 1.000 & 1.000 & - \\
6 & 0.603 & 0.629 & 0.959 & irs \\
7 & 1.000 & 1.000 & 1.000 & - \\
8 & 0.460 & 0.797 & 0.577 & irs \\
9 & 0.465 & 0.650 & 0.716 & irs \\
10 & 1.000 & 1.000 & 1.000 & - \\
mean & 0.756 & 0.861 & 0.872 & \\
\hline
\end{tabular}

Note. crste is the technical efficiency (comprehensive efficiency) that does not consider the return of scale; vrste is the technical efficiency (pure technical efficiency) that considers the return of scale; scale is the efficiency of scale (scale efficiency) that considers the return of scale, and pure technical efficiency and scale efficiency are The subdivision of overall efficiency; irs, -, drs respectively represent increasing, constant, and decreasing returns to scale.

We use DEAP software to analyze the input and output data, and obtain the comprehensive efficiency, pure technical efficiency and scale efficiency values during the study period, as shown in Table 4. 
Table 4 Overall performance during the study period

\begin{tabular}{lllll}
\hline & 2016 & 2017 & 2018 & 2019 \\
\hline techch & 0.699 & 0.699 & 0.718 & 0.756 \\
pech & 0.853 & 0.920 & 0.799 & 0.861 \\
sech & 0.816 & 0.763 & 0.877 & 0.872 \\
\hline
\end{tabular}

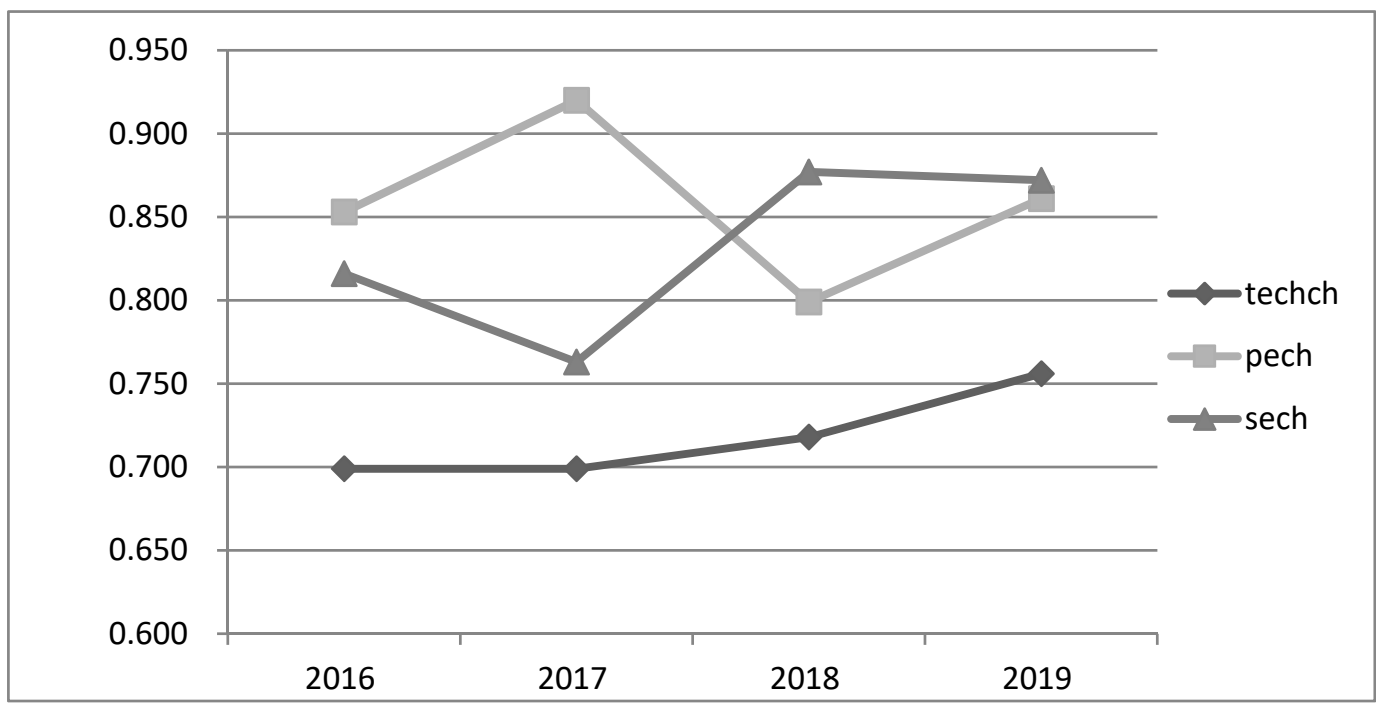

Figure 1. Trends in the overall efficiency of technological innovation, pure technical efficiency and scale efficiency

In terms of comprehensive efficiency, it can be seen from Table 4 and Figure 1 that during the four years from 2016 to 2019, the comprehensive efficiency of 10 military-civilian integration enterprises has not yet reached the DEA effective. The comprehensive efficiency value in 2019 is 0.759 , indicating that there is still $24.1 \%$ waste of resources, which is obviously ineffective. The lowest value of the overall efficiency is 0.460 of the optical cable. However, there is an upward trend in overall efficiency. With the deep development of military-civilian integration, overall technical efficiency has begun to increase rapidly.

In terms of pure technical efficiency, these 10 companies experienced a trough in 2018, with the lowest value being 0.799 , followed by the lowest value of 0.853 in 2016 . The lowest pure technical efficiency is 0.629 of Guorui Technology. The inefficiency of pure technical efficiency in a certain extent reflects some problems such as irrational corporate capital structure, insufficient technological innovation, and poor internal management.

In terms of economies of scale, under the circumstance that other conditions remain unchanged, when the production factors input by the enterprise increase or decrease in the same proportion, the production scale of the enterprise changes. If the increase in output or income is greater than the increase in each factor of production, it means that the scale of production is increasing. If the increase in output or income is equal to the increase in various factors of production, it means that the scale of production remains unchanged. If the increase in output or income is less than the increase in various factors of production, it means that the scale of production is decreasing. It can be seen from Table 2 that the average scale efficiency of the 10 military-civilian listed companies is 0.872 in 2019, indicating that the scale efficiency DEA has not been effective, and the overall scale efficiency of military-civilian integrated companies is low. Specifically, there are only 4 companies with scale efficiency equal to 1 . The scale efficiency of the remaining six companies is less than 1 , and the scale level has not reached the DEA effect, indicating that there is still room for development to improve the production efficiency of enterprises by expanding the production scale, which creates the conditions for improving technological innovation performance.

\subsection{Dynamic Analysis}

Since the model can only do the static analysis of enterprise technological innovation performance, in order to make the measurement results more scientific and effective, this paper applies the Malmquist index model to measure the dynamic efficiency of selected financial data, so as to study the efficiency dynamic changes of 
technological innovation of military-civilian integrated enterprises in the past 4 years. The calculation results are shown in Table 5.

Table 5. Malmquist index and decomposition

\begin{tabular}{|c|c|c|c|c|c|c|}
\hline No. & Firm & effch & techch & pech & sech & tfpch \\
\hline 1 & Xinhaiyi & 1.460 & 0.914 & 1.426 & 1.024 & 1.335 \\
\hline 2 & Yinhe Electronics & 1.015 & 1.110 & 0.873 & 1.163 & 1.127 \\
\hline 3 & Tianwo Technology & 1.587 & 0.709 & 1.031 & 1.540 & 1.125 \\
\hline 4 & Tongda Power & 0.882 & 0.871 & 1.000 & 0.882 & 0.768 \\
\hline 5 & Helenzer & 1.000 & 0.922 & 1.000 & 1.000 & 0.922 \\
\hline 6 & $\begin{array}{l}\text { Electric Power } \\
\text { Research Institute }\end{array}$ & 0.885 & 0.793 & 0.896 & 0.987 & 0.702 \\
\hline 7 & Tongguang Cable & 1.118 & 1.066 & 1.076 & 1.040 & 1.193 \\
\hline 8 & Ruite Co & 0.835 & 0.983 & 0.970 & 0.861 & 0.821 \\
\hline 9 & Guorui Technology & 0.975 & 0.820 & 0.917 & 1.062 & 0.799 \\
\hline \multirow[t]{2}{*}{10} & Suzhou High-tech & 1.000 & 0.905 & 1.000 & 1.000 & 0.905 \\
\hline & mean & 1.053 & 0.902 & 1.010 & 1.043 & 0.950 \\
\hline
\end{tabular}

It can be seen from Table 5 that among the listed companies in Jiangsu's military-civilian integration from 2016 to 2019, the total factor productivity (TFPCH) of the four companies, Xinhaiyi, Yinhe Electronics, Tianwo Technology and Tongguang Cable, were greater than 1, indicating that the innovative technology efficiency is on the rise, and the efficiency of the remaining 6 companies is not performing well, and the resource utilization rate is still at a low level. The performance difference between the sample company's technical efficiency (comprehensive efficiency) value and the pure technical efficiency value is mainly affected by the differences in the company's management level. The overall scale efficiency value of the sample company is relatively high, indicating the production scale and input factors have basically achieved optimal matching, which provides favorable conditions for improving the efficiency of technological innovation. After comparison, it is found that technical efficiency, management level and scale efficiency have all increased slightly in 2019.

Among the dynamic indicators, the low rate of change in technological progress of these companies is a comprehensive reflection of backward production technology, which also confirms the previous analysis. After analyzing the output, we found there is room for improvement in sample companies in terms of capital utilization, enterprise management, production technology, technological innovation, factor input and production scale.

\section{Conclusion}

This paper measures the technological innovation performance of military-civilian integration enterprises from both static and dynamic aspects, the results of this study show that in the initial development stage of military-civilian integration, the number of effective patents and new product projects that can be converted by military-civilian enterprises is so small in Jiangsu Province, which results in commonly unreasonable allocation and waste of resources. Therefore, enterprises should attach great importance to the actual effect of fund utilization, focus on solving the problem of fund utilization efficiency, and maximize the use of funds. At the same time, companies should pay attention to advancement and practicability when developing patents. They should not only focus on the quantity but ignore the quality of the patents, which results in a situation where patents cannot be transformed into profits. The direct reason for the generally low innovation performance of enterprises is the low resource utilization rate. The fundamental reason is that the technological progress of military-civilian integration enterprises has not kept pace with the current technological development, which has seriously affected the function of military-civilian integration and restricted the effect of capital utilization. The relative backwardness of technology directly causes the limitation of capital operation. Therefore, it is necessary for enterprises to re-examine the technical positioning and find the technological breakthrough that matches the enterprise. The uneven technological innovation performance of military-civilian enterprises in Jiangsu Province shows that there is a gap in capital utilization efficiency and management level between different companies, which has led to a large gap in the overall strength of various enterprises. Therefore, companies need to 
strengthen their own management capabilities.

According to the above conclusions, this paper puts forward the following suggestions:

1) Improve the technological level and technological innovation capabilities of enterprises. First of all, enterprises should clarify innovation strategies and regard science and technology as their core competitiveness. Secondly, increase investment in research and development funds to provide financial guarantees for corporate technological innovation. Thirdly, actively introduce high-end innovative talents to improve the overall quality of the technical talent team.

2) Improve the level of corporate capital operation and capital management capabilities. Accurately grasp the direction of capital operation and increase the utilization rate of capital. At the same time, a scientific supervision mechanism shall be established to ensure the effective functioning of funds.

3) Strengthen the building of enterprises' own capacity. Improve the level of corporate management and optimize the internal management system of the company.

4) Increase government supervision and guidance. By formulating relevant policies, such as tax incentives, financial discounts and other fiscal policies, guide corporate funds to flow to the national development industry. At the same time, strengthen the capital supervision of state-owned or state-holding enterprises, scientifically supervise corporate capital flow and capital use efficiency, establish and improve financial laws and regulations, implement equal treatment for enterprises of different sizes and different natures, so that they can fairly enjoy policy benefits.

\section{Acknowledgments}

This paper is supported by the Fundamental Research Funds for the Central Universities (No: NJ2018024).

\section{References}

Alic, J. A., Branscomb, L. M., \& Brooksh, et al. (1992). Beyond Spinoff: Military and Commercial Technologies in a Changing World. Boston: Harvard Business School Press.

Cosh, A. \& Hughes, A. (2012). Organization Structure and Innovation Performance in Environments. Small Business Economics, 39(2), 301-317.

Fang, Y. H., Wang, L., \& Tan, Q. M. (2017). Research on Operation Mechanism and Evaluation Index System of Military-civilian Integration Industry Innovation Platform. Journal of Information, 36(12), 198-206. https://doi.org/10.3969/j.issn.1002-1965

Han, B., \& Su, Y. (2018). Research on the Technological Innovation Performance of High-tech Enterprises Based on Two-stage DEA. Science and Management, 39(3), 11-16. https://doi.org/10.19571/j.cnki.1000-2995

He, Y. M., Wu, S. S., \& Yang, R. (2018). Research on Performance Evaluation of Technological Innovation in Military-civilian Enterprises. Technological Progress and Countermeasures, 35(4), 146-152. https://doi.org/10.6049/kjjbydc.201708X267

Hu, H. A., \& Liu, 1. J. (2015). An Empirical Analysis of the Innovation Synergy of Military-civilian Integration. Technological Progress and Countermeasures, 32(3), 121-126. https://doi.org/10.6049/kjjbydc.2014070120

Kulve, H. T., \& Smit, W. A. (2013). Civil-military Cooperation Strategies in Developing New Technologies. Research Policy, 32(6), 955-970.

Lan, D. X., Wu, Y. F. (2018). Research on the System and Mechanism Innovation Strategy of Military-civilian Integration Demonstration Zone from the Perspective of Complex System. Theory and Reform, (4), 79-91. https://doi.org/10.13553/j.cnki.llygg

Li, Y. J., \& Li, W. (2018) Research on Evaluation of Innovation Performance of High-tech Enterprises in Heilongiiang Province. Research and Practice of Innovation and Entrepreneurship Theory, 1(20), 114-117.

Ross, K. G., Wisecarver, M., \& Thornson, C. A. (2017). Development of a Competency Model for Civil-military Teaming. Advances in Intelligent Systems and Computing, 480.

Shuang, H. J. (2013). Research on the Components of Military-civilian Integration Technology Innovation Collaboration. Modern Management Science, 31(2). https://doi.org/10.3969/j.issn.1007-368X

Yang, X. X., Chen, B., \& Zhang, H. (2020). Military-civilian Integration Collaborative Innovation, Spatial Correlation and Defense Innovation Performance. Technological Progress and Countermeasures, 37(09), 145-152. https://doi.org/10.6049/kjjbydc 
Zhao, Y., Zhou, Y., \& Chen, L.Y. (2019). Research on the Decomposition of Construction Objectives of Military-civilian Integration Technology Innovation System. Technology Management Research, 39(23), 41-46. https://doi.org/10.3969/j.issn.1000-7695

\section{Copyrights}

Copyright for this article is retained by the author(s), with first publication rights granted to the journal.

This is an open-access article distributed under the terms and conditions of the Creative Commons Attribution license (http://creativecommons.org/licenses/by/4.0/). 